\title{
The Key to Improve Performance:Employee Engagement
}

\author{
Dr. Jai Prakash Tripathi \\ Research Guide \& Dean, SOMS,-Sri Satya Sai University of Technology \& Medical Sciences, Sehore (M.P.), India. \\ Mr. Sunil Sharma \\ Research Scholar \& Asst. Prof, SOMS-Sri Satya Sai University of Technology \& Medical Sciences, Sehore (M.P.),
}

\begin{abstract}
Employee engagement is an endless build that touches all parts of human asset administration features we know until now. On the off chance that all aspects of HR is not tended to in fitting way, Employees neglect to completely draw in themselves in their employment in the reaction to such sort of bungle. The build representative engagement is based on the establishment of prior ideas like occupation fulfillment, Employee responsibility and Organizational citizenship conduct. Despite the fact that it is identified with and includes these ideas, representative engagement is more extensive in degree. Representative engagement is more grounded indicator of positive authoritative execution plainly demonstrating the two-route relationship amongst business and Employee contrasted with the three before builds: work fulfillment, representative responsibility and hierarchical citizenship conduct. Drawn in representatives are sincerely joined to their association and very required in their occupation with an awesome excitement for the accomplishment of their boss, going additional mile past the livelihood authoritative assentation.
\end{abstract}

Keywords: Employee engagement, Employee commitment, Organizational citizenship behavior, Job satisfaction

\section{Introduction}

Administrators unequivocally concur that this century requests more effectiveness and efficiency than some other times ever. Organizations are endeavoring to expand their execution. Chiefs have been thinking about numerous difficulties to succeed putting their organization in front of contenders. To help supervisors oversee, diverse researchers, analysts and advisors have been contributing their part demonstrating the most ideal ways they believe are valuable to chiefs. Among those proposed methods, ideas like Total Quality Management (TQM) and Business Process Reengineering (BPR) earned acknowledgment from numerous creators in the second 50\% of twentieth century and were discovered useful in expanding hierarchical execution by concentrating on operational and procedure enhancements. They were/all the while being utilized as instruments for administration as a part of their push to arrange, execute and control of the wanted changes in the operational quality.

Because of innovation, these days business organizations are making utilization of cutting edge methods of operation. As modernity of advancements keeps on developing, they posture more difficulties for directors since associations will need to need more number of workers with expanded specialized and expert abilities. These learning Employees can not be made do with old styles of totalitarian administration. They expect operational selfrule, work fulfillment and status. It is a direct result of these actualities that consideration of administrators is moving towards representatives' side of associations. From last quarter of twentieth century onwards, ideas like representative duty and Organizational Citizenship Behavior (OCB) began to show up on the ground that effectiveness and profitability exist in the workers' capacity and responsibility. Administrators' eye is on the most proficient method to keep representatives occupied with their employment. Managers now understand that by concentrating on representative engagement, they can make more proficient and profitable workforce. Any activities of change which are taken by administration can not be productive without wilful contribution and engagement of workers. Representative engagement as an idea is immense. This article limits itself to talk about just the fundamental ideas on worker engagement taking into account late literary works. It has four noteworthy parts.

Firstly, the article investigates the advancement of the idea, its definition and how it is not quite the same as the prior ideas, for example, Commitment, Organizational Citizenship Behavior (OCB) and work fulfillment.Besides, the article talks about the elements or drivers prompting engagement.Thirdly, it subtle elements the effect of representative engagement on hierarchical execution markers or business results, for example, gainfulness, consumer loyalty, organization development, efficiency and others calling attention to its advantages and significance to associations. At long last, the article recommends methodologies the organizations ought to take up to keep representatives occupied with their occupations.

\subsection{Evolution of Employee Engagement}

\section{Evolution of Employee Engagement and its Definition}

Most references relate representative engagement to review houses and consultancies. It is less taken as a 
scholastic build. The idea is moderately new for HRM and showed up in the literary works for about two decades (Rafferty, Maben, West and Robinson, 2005; Melcrum Publishing, 2005; Ellis and Sorensen, 2007).The develop, worker engagement exudes from two ideas that have won scholarly acknowledgment and have been the subjects of observational examination Commitment and Organizational Citizen Behavior (OCB) (Robinson, Perryman and Hayday, 2004; Rafferty et al., 2005). Worker engagement has likenesses to and covers with the above two ideas.Robinson et al. (2004) state that neither responsibility nor OCB reflect adequately two parts of engagementits two-way nature, and the degree to which connected with workers are relied upon to have a component of business mindfulness, despite the fact that it gives the idea that engagement covers with the two ideas. Rafferty et al (2005) additionally recognize worker engagement and the two earlier ideas Commitment and OCB, on the ground that engagement unmistakably shows that it is a two-way common procedure between the representative and the association.

\subsection{Definition of Employee Engagement}

To date, there is no single and for the most part acknowledged definition for the term representative engagement. This is apparent on the off chance that one takes a gander at the definitions sent for the term by three understood examination associations in human asset zone, not to mention singular analysts. The following are the definitions: Perrin's Global Workforce Study (2003) utilizes the definition "representatives' eagerness and capacity to help their organization succeed, generally by giving optional exertion on an economical premise." According to the study, engagement is influenced by numerous variables which include both enthusiastic and balanced components identifying with work and the general work experience. Gallup association characterizes worker engagement as the contribution with and eagerness for work. Gallup as referred to by Dernovsek (2008) compares representative engagement to a positive workers' enthusiastic connection and workers' dedication.Robinson et al. (2004) characterize representative engagement as "an inspirational state of mind held by the worker towards the association and its quality. A drew in worker knows about business connection, and works with associates to enhance execution inside the occupation for the advantage of the association. The association must work to create and sustain engagement, which requires a two-path relationship amongst manager and worker."

This decision and definition sent by Institute of Employment Studies gives an unmistakable understanding that worker engagement is the consequence of two-path relationship amongst business and representative indicating out that there are things be finished by both sides. Moreover, Fernandez (2007) demonstrates the refinement between occupation fulfillment, the outstanding build in administration, and engagement fighting that worker fulfillment is not the same as representative engagement and since supervisors can not depend on representative fulfillment to hold the best and the brightest, worker engagement turns into a basic idea. Different analysts accept position fulfillment as a piece of engagement, however it can just mirror a shallow, value-based relationship that is just in the same class as the association's last round of advantages and rewards; Engagement is about enthusiasm and duty the eagerness to contribute oneself and extend one's optional push to help the business succeed, which is past straightforward fulfillment with the job plan or fundamental unwaveringness to the business (BlessingWhite, 2008; Erickson, 2005; Macey and Schnieder ,2008). Along these lines, the full engagement condition is gotten by adjusting most extreme employment fulfillment and greatest occupation commitment. Stephen Young, the official executive of Towers Perrin, additionally recognizes work fulfillment and engagement fighting that loneengagement (not fulfillment) is the most grounded indicator of authoritative execution (Human Resources, 2007). Late investigates additionally show that Employee duty and OCB are essential parts and indicators of worker engagement in that dedication is conceptualized as positive connection and eagerness to apply vitality for accomplishment of the association, feeling glad for being an individual from that association and recognizing oneself with it and OCB is a conduct saw inside the work setting that exhibits itself through taking innovative activities proactively looking for chances to contribute one's ideal and going additional mile past vocation contract. In any case, these builds constitute the greater develop representative engagement and they can not freely go about as a swap for engagement (Macey and Schneider, 2008; Robinson et al, 2004).

The terrible news for administration is that worldwide reviews led by overview houses and research associations demonstrate that huge size of workers are separated being doubtful of any hierarchical activity or correspondence and rather more probable enjoying infectious pessimism (Dernovsek, 2008; Perrin, 2003; Ellis and Sorensen, 2007; Blessing White, 2008). The issue with these studies is that they utilize their own things to gauge representative engagement. On the off chance that took a gander at the accessible literary works on measuring worker engagement, one would get shockingly a few estimation things to the degree that it appears to be changed builds are being measured (Robinson et al, 2004; Cohen and Higgins, 2007; Perrin, 2003; Ellis and Sorenson, 2007; Dernovsek, 2008). Future looks into are required to think of clear definition and measurements of worker engagement on premise of which the level of engagement can be allotted along these lines indicating supervisors the guide for completely captivating representatives in their employment. As the well-known adage goes "what you can't gauge, you can't oversee". In this way, there is a call for future scrutinizes, as recommended by Endres and Mancheno-Smoak (2008), to characterize engagement in clear terms to dodge elucidation by consequent clients providing for the build distinctive implications. 


\section{Drivers of Employee Engagement}

Numerous examines have attempted to distinguish components prompting representative engagement and created models to draw suggestions for supervisors. Their analysis means to decide the drivers that will expand worker engagement level.As indicated by Penna research report (2007) which means at work can possibly be significant method for conveying bosses and representatives nearer together to the event of both where representatives encounter a feeling of group, the space to act naturally and the chance to make a commitment, they discover meaning. Representatives need to work in the associations in which they discover importance at work. Penna (2007) scientists have likewise concocted another model they called "Chain of importance of engagement" which looks like Maslow's need order model. In the main issue there are fundamental needs of pay and advantages. Once a representative fulfilled these requirements, then the worker looks to advancement open doors, the likelihood for advancement and after that initiative style will be acquainted with the blend in the model. At long last, when all the above refered to lower level yearnings have been fulfilled the representative looks to an arrangement of significant worth importance, which is shown by a genuine feeling of association, a typical reason and a common feeling of importance at work. The Blessing White (2006) study has found that very nearly two third's (60\%) of the studied representatives need more chances to become forward to stay fulfilled in their occupations. Solid chief worker relationship is a urgent fixing in the representative engagement and maintenance recipe.

Improvement Dimensions International (DDI, 2005) states that a director must do five things to make a very connected with workforce. They are:

- Align endeavors with technique

- Empower

- Promote and empower cooperation and coordinated effort

- Help individuals develop and create

- Provide backing and acknowledgment where proper

The Towers Perrin Talent Report (2003) recognizes the main ten work place qualities which will bring about representative engagement. The main three among the ten drivers recorded by Perrin are: Senior administration's enthusiasm for representatives' prosperity, Challenging work and Decision making power. In the wake of looking over 10,000 NHS representatives in Great Britain, Institute of Employment Studies (Robinson et al., 2004) brings up that the key driver of worker engagement is a feeling of feeling esteemed and included, which has the segments, for example, association in basic leadership, the degree to which workers feel ready to voice their thoughts, the open doors representatives need to build up their occupations and the degree to which the association is worried for representatives' wellbeing and prosperity.

CIPD (2006) on the premise of its study of 2000 workers from crosswise over Great Britain shows that correspondence is the top need to lead representatives to engagement. The report singles out having the chance to encourage their perspectives and suppositions upwards as the most vital driver of individuals' engagement. The report additionally distinguishes the significance of being kept educated about what is happening in the association. The most seasoned counseling association in directing engagement study, Gallup has found that the chief is the way to a connected with work power. James Clifton, CEO of Gallup association shows that representatives who have dear fellowships at work are more connected with Employees (Clifton, 2008). Vance (2006) clarifies the way that representative engagement is inseparably connected with manager rehearses. To reveal insight into the routes in which business hones influence work execution and engagement, he displays an occupation execution model. As per him, Employee engagement is the result of individual qualities, for example, information, aptitudes, capacities, demeanor, dispositions and identity, hierarchical connection which incorporates authority, physical setting and social setting and HR rehearses that straightforwardly influence the individual, procedure and setting parts of occupation execution.Most drivers that are found to prompt worker engagement are non-monetary in their temperament. In this manner, any association who has conferred initiative can accomplish the wanted level of engagement with less cost of doing it. This doesn't imply that administrators ought to overlook the monetary part of their representatives. Truth be told, execution ought to be connected with prize. By and by, this is essentially to rehash the familiar axiom of Human Relations Movement which goes "as social being, human asset is not spurred by cash alone." As Buckingham and Coffman (2005) said, pay and advantages are similarly imperative to each representative, great or awful. An organization's compensation ought to in any event be equivalent to the business sector normal. Be that as it may, offering pay and advantages bundle up for sale to the public levels, which is a sensible initial step, won't take an organization exceptionally far-they resemble tickets to the ballpark, - they can get the organization into the diversion, yet can't help it win.

\section{Employee Engagement and Organizational Performance}

Why ought to organizations put resources into representative engagement? The answer is on the grounds that worker engagement is interlaced altogether with critical business results. In this part we will perceive how worker engagement impacts hierarchical execution in the light of different examination works done. Concentrates on have discovered positive relationship between worker engagement and authoritative execution results: 
representative maintenance, efficiency, gainfulness, client unwaveringness and security. Scrutinizes additionally show that the more drew in representatives are, the more probable their boss is to surpass the business normal in its income development. Worker engagement is observed to be higher in twofold digit development organizations. Explore likewise demonstrates that engagement is decidedly identified with consumer loyalty (Coffman, 2000; Ellis and Sorensen, 2007; Towers Perrin Talent Report, 2003; Hewitt Associates, 2004; Heintzman and Marson, 2005; Coffman and Gonzalez-Molina, 2002). Drawn in representative reliably exhibits three general practices which enhance hierarchical execution: O Say-the representative backers for the association to co-Employees, and alludes potential workers and clients $\mathrm{O}$ Stay-the representative has a serious craving to be an individual from the association in spite of chances to work somewhere else O Strive-the representative applies additional time, exertion and activity to add to the achievement of the business ( Baumruk and Gorman, 2006)

What will happen to an association if its representatives are separated? Workers who are not locked in are liable to turn (squandering their exertion and ability on assignments that may not make any difference much), settling (surely don't indicate full duty, not sufficiently disappointed to make a break) and part (they are not adhering around for things to change in their association), have significantly more apprehensions about their association regarding execution measures, for example, consumer loyalty (BlessingWhite, 2006; Perrin Report, 2003). Meere (2005) in view of the study led by ISR on 360000 workers from 41 organizations on the planet's 10 monetarily solid nations finds that both working edge and net overall revenues lessened over a three year time frame in organizations with low engagement, while these measures expanded over the predetermined period in organizations with large amounts of engagement.

Budgetary News, March 2001, as refered to by Accord Management Systems (2004), uncovers that withdrew representatives will probably cost their association. As indicated by the report, Employees who are withdrawn:

- $\quad$ Miss a normal of 3.5 more days for every

- Are less profitable

- $\quad$ Cost the US economy $\$ 292$ to $\$ 355$ billion every year

\section{Employee Engagement Strategies}

So far we have talked about the advancement and meaning of worker engagement, the variables that influence it and significance of representative engagement clarifying how it is connected to business execution. Presently, at this stage any curious peruser may pose a question: So what? Worker engagement methodologies recorded underneath answer this inquiry. Keeping in mind the end goal to have drawn in representatives in any association, administrators need to take a gander at the accompanying ten focuses. We can call these focuses "tablets" since it is trusted that they will cure worker separation infections. Take these ten tablets:

1. Start it on the very first moment: Most associations do have clear new ability procurement techniques. Nonetheless, they need worker maintenance techniques. Powerful enlistment and introduction projects are the principal building squares to be laid on the main day of the new worker. Directors ought to be watchful in pooling out the potential ability of the new representative through powerful enlistment. The recently enlisted representative ought to be given both general introduction which is identified with the organization mission, vision, qualities, approaches and strategies and occupation particular introduction, for example, his/her employment obligations, and duties, objectives and current needs of the office to which the worker has a place all together with empower him/her to create practical occupation desires and decrease part strife that may emerge later on. After the enlisting choice is made, the chief needs to guarantee part ability fit while setting a representative in a specific position and apply every single administrative exertion expected to hold that ability in the association.

2. Start it from the top: Employee engagement requires authority responsibility through building up clear mission, vision and qualities. Unless the general population at the top have faith in it, own it, pass it down to chiefs and representatives, and improve their authority, worker engagement will never be more than only a "corporate prevailing fashion" or "another HR thing". Worker engagement does not require lip-benefit rather committed heart and activity situated administration from top administration. It requires "Driving by Being illustration"

3. Enhance worker engagement through two-way correspondence: Managers ought to advance two-way correspondence. Workers are not sets of pots to which you spill out your thoughts without allowing them to have a say on issues that matter to their employment and life. Clear and predictable correspondence of what is anticipated from them prepares for drew in workforce. Include your kin and dependably indicate appreciation to their info. Offer force with your workers through participative basic leadership so they would feel feeling of belongingness in this manner expanding their engagement in acknowledging it.

4. Give acceptable open doors for improvement and progression: Encourage autonomous thoroughly considering giving them more occupation self-governance so representatives will have an opportunity to make their own particular flexibility of picking their own most ideal method for doing their employment inasmuch as they are creating the normal result. Oversee through results instead of attempting to deal with every one of the 
procedures by which that outcome is accomplished.

5. Ensure that representatives have all that they have to carry out their occupations: Managers are relied upon to ensure that workers have every one of the assets, for example, physical or material, monetary and data assets keeping in mind the end goal to successfully carry out their employment.

6. Give workers suitable preparing: Help representatives overhaul themselves expanding their insight and aptitudes through giving proper trainings. For the most part it is comprehended that when representatives become acquainted with additional about their employment, their certainty increments there by having the capacity to work without much supervision from their prompt directors which thusly constructs their selfadequacy and responsibility.

7. Have in number criticism framework: Companies ought to build up an execution administration framework which considers supervisors and workers responsible for the level of engagement they have appeared. Directing consistent study of worker engagement level makes out components that make representatives locked in. In the wake of concluding the study, it is fitting to decide every one of the variables that driving engagement in the association, then tight down the rundown of components to concentrate on a few territories. It is imperative that associations start with a fixation on the elements that will have the most effect to the representatives and put vitality around enhancing these zones as it might be hard to address all elements without a moment's delay. Administrators ought to be behind such review comes about and create activity situated arrangements that are particular, quantifiable, and responsible and time-bound.

8. Incentives have a section to play: Managers ought to work out both monetary and non-money related advantages for representatives who demonstrate more engagement in their employments. A few administration hypotheses have demonstrated that at the point when representatives get more pay, acknowledgment and adulate, they have a tendency to apply more exertion into their employment. There ought to be a reasonable connection amongst execution and motivations given to the representatives.

9. Build a particular corporate society: Companies ought to advance a solid work society in which the objectives and estimations of directors are adjusted over all work segments. Organizations that construct a society of shared admiration by keeping examples of overcoming adversity alive won't just keep their current representatives drew in additionally they absolve the new approaching representatives with this infectious soul of work society.

10. Focus on top-performing representatives: A study directed by Watson Wyatt Worldwide in 2004/05 on HR practices of 50 expansive USA firms demonstrates that high-performing associations are concentrating on drawing in their top-performing workers. As per the finding of the same examination, what high-performing firms are doing is the thing that top-performing representatives are requesting and this decreases the turnover of high-performing workers and accordingly prompts top business execution.

Note that there is absence of adequate writing on what could be the difficulties that entrap with pioneers' push to enhance their worker engagement scores. Most inquires about on the territory concentrate on distinguishing the drivers or variables prompting engagement; nonetheless, neglecting to demonstrate plainly enunciated procedures to get representatives occupied with their work. The recommended techniques will have budgetary ramifications on associations. In any case, explores don't clearly demonstrate the expense of endeavors went for expanding representative engagement.

\section{Conclusion}

Till date, there is no by and large acknowledged definition for representative engagement. In any case, there is developing agreement among the creators that the build is recognizable from related ideas in administration, for example, worker responsibility, authoritative citizenship conduct and occupation fulfillment in such a way, to the point that representative engagement unmistakably mirrors the two-route trade of exertion amongst workers and bosses, and it has extended importance past the previously mentioned develops. Research on engagement is still on its early stages, endeavoring to think of all the more obvious and satisfactory definition.

Most studies show that inclination esteemed by administration, two-path correspondence amongst administration and representatives, administration's enthusiasm for workers' prosperity and giving more open doors for workers to develop are the top drivers of worker engagement. By the by, as studies demonstrate, representatives don't give much significance to pay and advantages. This may be the situation on the grounds that all the reviews were made in organizations working in monetarily well-to-do nations. The needs of drivers may have changed if comparative reviews were experienced in other underdeveloped nations, similar to African nations. In this way, there is a requirement for more worldwide reviews including more number of nations.

The literary works demonstrate that representative engagement is firmly connected with authoritative execution results. Organizations with drew in workers have higher representative maintenance as a consequence of lessened turnover and diminished expectation to leave the organization, efficiency, gainfulness, development and consumer loyalty. Then again, organizations with withdrew workers experience the ill effects of misuse of exertion and drain ability, procure less duty from the representatives, face expanded truancy and have less client 
introduction, less profitability, and decreased working edges and net revenues. Most looks into accentuate only the significance and positive effects of worker engagement on the business results, neglecting to give the money saving advantage examination to engagement choices. As some other administration choices, engagement choice ought to be assessed regarding both its advantages and its related expenses, without giving more prominent

accentuation to neither of the two, not to predisposition the leaders. In this way there is a need to think about the cost part of engagement choices. The astounding truth is, the discoveries of today's inquires about, can be utilized as foundation for the working of complete embodiment to the develop. Besides, a significant part of the works identified with "worker engagement" develop is ascribed to study houses and consultancies. Along these lines, there is a requirement for the scholarly world to explore this new develop and think of an unmistakable definition and measurements that will be utilized for measuring representative engagement defending the significance of engagement idea. Else, it will pass away in a matter of seconds the same number of other human asset prevailing fashions did.Discoveries of different investigates propose their own particular techniques with a specific end goal to keep representatives locked in. Here in this article ten focuses or methodologies called 'the ten tablets" were proposed to keep workers locked in. For supervisors, work of worker engagement begins at the very beginning through compelling enrollment and introduction program, the work of representative engagement starts from the top as it is unfathomable to have drawn in individuals in the associations where there are no connected with initiative. Directors ought to upgrade two-way correspondence, guarantee that representatives have every one of the assets they have to carry out their occupation, give proper preparing to expand their insight and expertise, set up prize components in which great job is compensated through different monetary and non-money related impetuses, construct an unmistakable corporate society that empowers diligent work and keeps examples of overcoming adversity alive, build up a solid execution administration framework which considers supervisors and representatives responsible for the conduct they convey to the working environment, place concentrate on topperforming representatives to decrease their turnover and keep up or increment business execution.

\section{References}

[1]. Accord Management Systems. (2004). Employee Engagement Strategy: A Strategy of Analysis to Move from Employee Satisfaction to Engagement. [Online] Available: www.accordsyst.com/papers/engagement_wp.pdf (March 3, 2009)

[2]. Baumruk R., and Gorman B. (2006). Why managers are crucial to increasing engagement. Melcrum Publishing.

[3]. Blessing White. (2006). Employee Engagement Report 2006 BlessingWhite, Inc. Princeton, New Jersey. [Online] Available: www.blessingwhite.com (November 15, 2008)

[4]. Blessing White. (2008). The Employee Engagement Equation in India. Presented by BlessingWhite and HR Anexi. [Online] Available: www.blessingwhite.com (November 15, 2008)

[5]. Buckingham M., and Coffman C. (2005). First, break all the rules. Pocket Books, London. Chartered Institute of Personnel and Development. (2006). Reflections on employee Engagement: Change agenda. CIPD: London. [Online] Available: http://www.cipd.co.uk/changeagendas (November10, 2008)

[6]. Clifton, James K. (2008). Engaging your employees: Six keys to understanding the new workplace. 2002 SHRM Foundation Thought Leaders Remarks. Society for Human Resource Management

[7]. Coffman C. (2000). Is Your Company Bleeding Talent? How to become a true "employer of choice”. The Gallup Management Journal, 2000. The Gallup Organization, Princeton, NJ

[8]. Coffman, C., and Gonzalez-Molina, G. (2002). Follow this Path: How the world's greatest organizations drive growth by unleashing human potential. New York Warner Books, Inc.

[9]. Cohen G., and Higgins N. J. (2007). Employee Engagement: The secret of highly performing organizations.

[10]. Journal of Applied Human Capital Management, Vol 1 Number 2007.

[11]. Dernovsek D. (2008). Creating highly engaged and committed employee starts at the top and ends at the bottom line Credit Union Magazine, May 2008. Credit Union National Association, Inc.

[12]. Development Dimensions International. (2005). (Predicting Employee Engagement MRKSRR12-1005 Development Dimensions International, Inc., MMV. [Online] Available:www.ddiworld.com (October 30,2008)

[13]. Ellis C. M., and Sorensen A. (2007). Assessing Employee Engagement: The Key to Improving Productivity. Perspectives, vol .15, Issue 1 The Segal Group, Inc.

[14]. Endres G. M., and Mancheno-Smoak L. (2008). The Human resource Craze: Human Performance Improvement and Employee Engagement. Organizational Development Journal, Spring 2008; 26, 1; ABI/ INFORM Global pg 69-78

[15]. Erickson, T.J. (2005). Testimony submitted before the US Senate Committee on Health, Education, Labour and Pensions, May 26.

[16]. Fernandez. C.P. (2007). Employee engagement. Journal of Public Health Management and Practice. [Online] Available: http://find.galegroup.com. (October 30, 2008)

[17]. Heintzman R., and Marson B. (2005). People, service and trust: Links in a public sector service value chain.

[18]. International Review of Administrative Studies, Vol 7 (4) December 2005, pp 549-575.

[19]. Hewitt Associates. (2004). Employee engagement higher at double digit growth companies. Research Brief. Hewitt associates LLC.

[20]. Human Resources. (2007). Research: Employee engagement ROI-rules of engagement [Online] Available: http://global. factiva. com/ha/ default.aspx. (October 28, 2008)

[21]. Macey W.H and Schneider B. (2008). The Meaning of Employee Engagement. Industrial and Organizational Psychology, 1 (2008), 330 .

[22]. Meere M. (2005). High cost of disengaged employees Victoria: Swinburne University of Technology. [Online] Available:http://www.swinburne.edu.au/ corporate /industrysolutions/ee/ reports/ Employee \%20 Engagement\% $20 \mathrm{in}$ dustry\% 20 Breifing\%20 Paper\%20Dec\%202005\%20.pdf (October 30, 2008)

[23]. Melcrum publishing. (2005). Employee engagement: How to build a high-performance workforce. An independent Melcrum Research Report Executive Summary.

[24]. Penna (2007). Meaning at Work Research Report. [Online] Available: http:// www. e-penna.com/ newsopinion /research.aspx (November10, 2008) 
[25]. Perrin T. (2003). Working Today: Understanding What Drives Employee Engagement The 2003 Towers Perrin Talent Report U.S Report. [Online] Available: http://www.towersperrin.com/tp/getwebcachedoc? Webc $=$ HRS /USA/2003/200309/Talent_2003.pdf (October 30, 2008)

[26]. Rafferty A. M., Maben J., West E., and Robinson D. (2005). What makes a good employer? Issue Paper 3 International Council of Nurses Geneva

[27]. Robinson D., Perryman S., and Hayday S. (2004). The Drivers of Employee Engagement Report 408, Institute for Employment Studies, UK

[28]. Vance R. J. (2006). Employee Engagement and Commitment SHRM Foundation, USA Watson Wyatt Worldwide. (2005). Employee Engagement and Talent Management. [Online] Available: www.watsonwyatt.com (March 3, 2009) 